\title{
La inseguridad ciudadana como proceso de "territorialización": aproximación conceptual y teórica
}

\author{
Jorge Adriano Moreno Ponce*
}

\begin{abstract}
Artículo recibido: 28 de agosto de 2015
Artículo aprobado: 15 de abril de 2016

Doi: http://dx.doi.org/10.12804/desafios28.2.2016.04

Para citar este artículo: Moreno Ponce, J. A. (2016). La inseguridad ciudadana como proceso de "territorialización": aproximación conceptual y teórica. Desafios, 28(2): 145-176. Doi: http://dx.doi.org/10.12804/desafios28.2.2016.04
\end{abstract}

\section{Resumen}

La territorialización de la inseguridad ciudadana como proceso asociado a un sector urbano considerado crítico y/ o vulnerable, se encuentra directamente relacionada con la apropiación sostenida en el tiempo de fenómenos como la inseguridady la criminalidad. Desde esa perspectiva, y a través de un ejercicio enunciativo de algunas zonas en Latinoamérica, Europa y Estados Unidos, que presentan determinados rasgos comunes, frente a lo definido como "territorialización de la inseguridad", se busca proponer una aproximación teórica y conceptual que devele la connotación sistémica y multicausal de los "procesos de territorialización de la inseguridad ciudadana", asi como visibilizar la dinámica y el alcance de este tipo de procesos, a partir del sujeto, las estructuras criminales, el espacio geográfico y su entorno.

Palabras clave: seguridad ciudadana, inseguridad, territorialización, criminalidad.

* Abogado de la Universidad Santo Tomás, especialista en Derecho Penal y Magister en Estudios Políticos e Internacionales, Universidad del Rosario, Bogotá, Colombia. Correo electrónico:kalifa1013@gmail.com 


\title{
Insecurity as a Process of "Territorialization": A Theoretical and Conceptual Approach
}

\begin{abstract}
The territorialization of insecurity as a process and associated with the urban sector seen as critical or vulnerable is directly related to the temporal appropriation of phenomena such as insecurity and crime. From such a perspective defined as "the territorialization of insecurity", and through a comparative exercise in some areas in Latin America, Europe and United States, the article proposes a theoretical and conceptual approach that embraces the systemic and multicausal connotation of the process of the territorialization of insecurity. In addition, it visualizes the dynamics and scope of this process from the perspectives of the subject, criminal structures, geographic space and its surroundings.
\end{abstract}

Keywords: Security, citizen, insecurity, territorialization, criminality.

\section{A insegurança cidadã como processo de "territorialização": aproximação conceitual e teórica}

\begin{abstract}
Resumo
A territorialização da insegurança cidadã como processo associado a um setor urbano considerado como crítico e/ ou vulnerável, encontra-se diretamente relacionada com a apropriação sustentada no tempo de fenómenos como a insegurança e a criminalidade. Desde essa perspectiva e através de um exercício enunciativo de algumas zonas na Latino-América, na Europa e nos Estados Unidos, que apresentam determinados rasgos comuns, frente ao definido como "territorialização da insegurança", se busca propor uma aproximação teórica e conceitual que revele a conotação sistémica e multicausal dos "processos de territorialização da insegurança cidadã", assim como visibilizar a dinâmica e o alcance deste tipo de processos, a partir do sujeito, as estruturas criminais, o espaço geográfico e o seu entorno.
\end{abstract}

Palavras- chave: Segurança cidadã, insegurança, territorialização, criminalidade. 


\section{Introducción}

Los problemas de inseguridad ciudadana en las grandes urbes del mundo presentan un origen multicausal. Mientras hay quienes le dan un papel protagónico a la desigualdad social como uno de los principales factores generadores de inseguridad y criminalidad, otros como Gizewski y Horner-Dixon (1995), consideran que "el crecimiento y deterioro urbano, al combinarse con factores como las crisis económicas y el debilitamiento de la acción del Estado, también puede contribuir a la inseguridad y al delito" (Red de Información de las Naciones Unidas sobre Justicia Penal-UNCJIN-, 1994, p. 17).

Bajo esa misma dinámica, existe la tendencia a identificar la pobreza como sinónimo de delito (Reyna \& Toche, 1999), atendiendo la incidencia que eventualmente pueda tener uno y otro en ciertas comunidades o sectores de la ciudad, haciéndolas más proclives a actos por fuera de la ley.

Por otro lado, el desarrollo urbanístico, las diferencias económicas, culturales, laborales y políticas (Cities Alliance, 2001) e inclusive, los escenarios generados a partir de procesos de postconflicto pueden acarrear contextos de inseguridad y criminalidad, particularmente en sectores urbanos centrales que por reunir ciertas características, son considerados como "vulnerables y/o críticos" o en su versión anglosajona, distressed urban areas o deprived neighbourhood (CESC, 2009).

Adicionalmente, Smith y Low (2006) advierten que los problemas de inseguridad y criminalidad, le pertenecen tanto a ciudades pobres como a ricas y que como tal, no se trata de una dificultad solo de urbes latinoamericanas, africanas o asiáticas, sino también, de ciudades europeas o norteamericanas. Por ejemplo, en Estados Unidos la mayor parte de los delitos ocurren en las sesenta y tres ciudades más grandes y prósperas, particularmente, en aquellas que presentan problemas de concentración de pobreza e hipersegregación (Massey \& Denton, 1993) y en barrios marginales o "puntos calientes" de

1 Sectores centrales urbanos cercados por la inseguridad y la criminalidad. 
la delincuencia, como Tenderloin y Bayview-Hunters Point (San Francisco), Woodlawn o "Cinturón negro" (Chicago), Avenida. 37 SW en Cocunut Grove (Boston), y Anacostia (Washington) (Davis, 1992; Sherman, Gartin \& Buerger, 1989; Sherman W. Lawrence \& Departamento de Criminología y Justicia Penal, 1996).

Asimismo, un estudio realizado en Europa por el Ministerio de Fomento de España sobre "áreas urbanas vulnerables" reseña que en Madrid existen diez zonas peligrosas, como resultado de una alta concentración de población económica, social, cultural y laboralmente abandonada, que por, supuesto, evidencia la interacción de fenómenos multidimensionales, propios de un escenario delictivo: Valdemingómez (Vallecas), El Ruedo (Moratalaz), San Fermín (Usera), Las Torres de San Cristóbal de los Ángeles (Villaverde), Pan Bendito y Alto de San Isidro (Carabanchel), la Colonia de los Olivos, Caño Roto y Calle Cullera (Latina) y Lavapiés (Centro) (Arias, 1998).

En Suramérica, Colombia, con ciudades como Bogotá, Medellín, Cali y Barranquilla, para citar solo unos ejemplos, no ha sido ajena a estos procesos de inseguridad. Su capital, Bogotá, registró en su momento con la denominada "Calle del Cartucho" y la "Calle del Bronx", dos escenarios sui generis de inseguridad ciudadana, que, además de constituirse en centros de producción del delito, fungieron como ejemplo de "suburbanización" del crimen. Solo existía una ley: impunidad frente a lo ilícito, la pobreza, la degradación humana, la marginalidad social y la criminalidad en todas sus manifestaciones.

Precisamente, la demarcación conceptual y aproximación teórica que propone el estudio en torno a lo denominado como "territorialización de la inseguridad ciudadana", emerge como una propuesta personal, producto de la explicación multicausal de la inseguridad y de las falencias teóricas que sobre el particular existen.

En esa medida, el estudio partió de la revisión y análisis de fuentes cuantitativas y cualitativas oficiales y no oficiales, provenientes de entidades, organismos, organizaciones no gubernamentales e instituciones académicas, vía método inductivo. De igual manera, se examinó 
investigaciones, documentos, reseñas, estudios, legislación y autores que hubiesen escrito sobre el tema, tanto en el ámbito internacional como nacional, con miras a determinar aquellos documentos que permitan dilucidar el significado y alcance de este tipo de manifestaciones agresivas de inseguridad y criminalidad en contextos urbanos y que ponen en evidencia todo un proceso de arraigo en áreas específicas, más allá de los denominados Hot Spots y barrios marginales.

De la misma forma, se indagó entorno a las principales tendencias conceptuales y teóricas, y a los debates suscitados durante las últimas décadas en materia de seguridad ciudadana, inseguridad urbana y criminalidad urbana, logrando estructurar un marco conceptual básico y un discurso teórico que permitiese no solo soportar el universo del artículo, sino también, diseñar y sustentar una propuesta racional que dé respuesta a la problemática planteada.

En consecuencia, se entenderá como "territorialización de la inseguridad ciudadana", la apropiación y captura sostenida en el tiempo de fenómenos como la inseguridad y la criminalidad, sobre determinadas zonas o barrios urbanos que, por las características históricas, socioeconómicas, políticas, culturales, laborales, geográficas y de mercado de quienes los habitan o frecuentan, se consideran como sectores "críticos ${ }^{2}$ y/o vulnerables". 3

Aquí, la expresión "crítico y/o vulnerable" se sugiere cada vez que sea necesario analizar casos a través de los cuales se manifieste:

\footnotetext{
2 Para el autor, se concibe como un "sector crítico", a aquellos escenarios citadinos que han exhibido, de manera cotidiana y sostenida en el tiempo, manifestaciones de inseguridad y criminalidad, y que por la complejización de los mismos y su injerencia en la seguridad de toda una ciudad, merecen recibir tal apelativo.

3 Definición dada por el autor de la investigación. Se entenderá por "Sectores Vulnerables", aquellos territorios (barrios, zonas urbanas ubicadas en el centro o periferia de la ciudad) que por sus condiciones culturales (valores, imaginarios, ideologías y comportamientos), socioeconómicas (pobreza, educación, comercio informal, espacio urbano deteriorado), geofísicas (territorio de difícil acceso, zonas sin servicios básicos adecuados o calles solitarias) y/o poblacionales (personas desplazadas, recicladores, habitantes de la calle, consumidores de droga, delincuentes comunes), son más propensos o proclives a padecer fenómenos de inseguridad y criminalidad.
} 
- Un barrio, calle o sector ubicado en el centro de la ciudad o en sus límites, como referente de inseguridad y/o criminalidad.

- La presencia de bandas u organizaciones criminales dedicadas al narcotrafico-microtrafico y/o venta de elementos ilegales, como armas de fuego y artículos hurtados, y que en casos extremos generan un poder económico, capaz de permitir el control de un sector, por encima de la presencia estatal.

- Disputas entre bandas por el control de un territorio.

- Control parcial o total de las bandas, mafias u organizaciones del sector (dominio), incluso de forma directa o indirecta del quehacer de sus habitantes y visitantes, que a menudo encuentran tres caminos: aprender a convivir con esa "territorialización de la inseguridad”, pertenecer a ella, es decir, delinquir, o simplemente guardar silencio frente a lo ilícito.

- Venta masiva de estupefacientes, al punto de considerar la zona como un "supermercado de droga", una "olla" o una "cloaca".

- Punto de encuentro de personas en condición de adicción a las drogas, comúnmente llamados drogadictos (habitantes y/o visitantes del sector).

- Economía informal que aglutina delitos como narcomenudeo, contrabando, reducidores y venta de productos hurtados.

- Centros de economía informal como el reciclaje, combinado con el consumo de estupefacientes y la comisión de delitos.

- Zonas que por sus condiciones geográficas no cuentan con una presencia permanente del Estado, lo que lleva a las estructuras criminales a regular las relaciones de los habitantes del sector.

- Áreas urbanas cercadas por la inseguridad donde quienes detentan el poder son las organizaciones criminales, el delito, la pobreza, el desempleo, el microtráfico, el deterioro urbanístico, la ausencia del Estado, la corrupción, la falta de control social, la exclusión y el miedo, como presupuesto de seguridad/inseguridad.

A partir de esta definición, la aproximación teórica de lo que constituye un escenario urbano territorializado por la inseguridad concentra el artículo alrededor de dos dimensiones: una subjetiva y otra objetiva. 
Si bien las teorías que se presentan a continuación no integran todo el universo que sobre el particular se podría referir y analizar, sí aglutina aspectos muy importantes de dicha problemática.

Así las cosas, la dimensión subjetiva busca brindar una respuesta al problema de "territorialización de la inseguridad", a partir del sujeto(s), entendido este como aquel individuo o estructura criminal que habita o frecuenta aquellas zonas que, en atención a las manifestaciones de inseguridad y criminalidad que presentan, son catalogadas como críticas y/o vulnerables. Por su parte, la dimensión objetiva está condicionada por el territorio y el entorno. El primero concebido como el espacio físico y sus elementos geográficos y urbanísticos, y el segundo, como aquellos factores inductores y/o facilitadores de inseguridad desde el punto de vista histórico, económico, social, político, laboral, geográfico, familiar y de mercado, entre otros, que condicionan, permiten o contribuyen a consolidar procesos de territorialización.

En ese orden de ideas, y para una mejor compresión del fenómeno en estudio, a lo largo del escrito se enuncian algunos escenarios en América Latina, Estados Unidos y Europa, que representan claros ejemplos de territorialización: la calle del Cartucho y la calle del Bronx (Colombia), la favela Rocinha (Brasil), Villa del Bajo Flores (Argentina), Tepito (México), el "South Bronx" (New York) y Secondigliano (Italia).

Estas experiencias responden a una serie de patrones comunes dentro del concepto de territorialización, pero con ello no se quiere significar que está frente a procesos idénticos, pues no obstante exhibir condiciones de inseguridad complejas, guardan su distancia frente a las manifestaciones sui generis que una y otra ha desplegado dentro de los contextos urbanos. De todas formas, su presentación es de gran utilidad, en la medida que contribuye a identificar las mutaciones que pueden generarse alrededor de este tipo de escenarios, así como aquellos factores detonantes de inseguridad y criminalidad que suelen repetirse en situaciones de tiempo y espacio. 


\section{Teorías explicativas de la territorialización, a partir del comportamiento individual delictivo y de las estructuras criminales}

A través de la historia son diversas las tendencias teóricas que, enmarcadas dentro de una dimensión subjetiva, toman como punto de referencia el comportamiento del individuo y el accionar de las estructuras criminales, para efectos de estudiar los fenómenos asociados a la inseguridad y el delito.

El presente análisis se concentra en dos de ellas: la teoría de la elección racional y la teoría de la actividad rutinaria.

Una y otra teoría permite explicar cómo un proceso de territorialización encuentra significancia en el comportamiento individual delictivo o en el actuar de una estructura criminal, como conducta habitual y racional de quienes residen o frecuentan zonas que por sus manifestaciones de inseguridad y criminalidad se catalogan como críticas y/o vulnerables.

Bajo esa perspectiva, estos postulados teóricos presentan como objeto de análisis al sujeto, entendido este como el individuo o grupo de individuos capaz de apropiarse de un determinado espacio y de aprovechar las condiciones de inseguridad que este le ofrece para vivir y delinquir. De igual manera, aportan valiosas luces en torno a los rasgos socio comportamentales repetitivos que suelen adoptar las personas que frecuentan y habitan un sector territorializado, al punto de considerar dichas zonas como espacios que no solo facilitan y brindan condiciones y oportunidades favorables para delinquir o para resguardarse del accionar de las autoridades, sino también, para posicionarse en ellas como una opción de vida, como una fuente de poder o como la única alternativa que el Estado y la sociedad le ofrecen para sobrevivir.

Así las cosas, aunque las oportunidades para cometer delitos se concentran en ciertos lugares y momentos, y eventualmente existen unas condiciones que favorecen su realización, a la luz de las teorías 
propuestas, la capacidad para decidir si se actúa por fuera o dentro del marco de la ley es responsabilidad exclusiva del individuo o de la estructura criminal, como sujetos tomadores de decisiones o en su defecto, como determinadores sobre quienes se convierten en instrumentos de su comportamiento por fuera de la ley.

Precisamente, Wilson, Herrnstein, Cornish \& Clarke (1998), señalan, a través de la teoría de la elección racional o de las decisiones racionales, que una conducta delictiva es resultado de una decisión racional, en tanto quienes cometen actividades contraviniendo las normas, buscan beneficios derivados de esa actividad, a partir de un análisis costobeneficio. El benefició al que alude esta teoría no necesariamente implica ser evaluado desde un contexto económico, como quiera que el mismo eventualmente puede estar circunscrito a meras situaciones de supervivencia.

De ahí que merezca afirmarse que los procesos de territorialización no suceden en forma espontánea, pues se requiere que a partir de un análisis costo-beneficio y la confluencia de una serie de factores, el individuo(s) adopte(n) una u otra decisión. Bajo esa perspectiva, al presentarse en un determinado sector la concurrencia de diversas variables, capaces de allanar un proceso de territorialización, este será siempre más atractivo, al compararlo con otros escenarios que no las proporcionan, más aún, para quienes su diario vivir es el delito o simplemente su adicción a las drogas, como suele suceder en gran parte de estos escenarios.

Por ello, cuando un sector se considera como crítico y/o vulnerable, atendiendo sus condiciones de inseguridad, no solo representa un caldo de cultivo frente a un futuro proceso de "territorialización", sino que facilita la dinámica de elección y de interpretación acerca de las posibilidades presentes y futuras para la consecución de un objetivo ilícito (éxito o fracaso/premio o sanción), así como de los recursos que necesitaría disponer en el momento (opciones espaciales y de tiempo e información) para llevar acabo su accionar. 
En consecuencia, un escenario "capturado" por la inseguridad es de dominio exclusivo del individuo(s), como sujeto(s) racional(es) capaz de tomar decisiones y de dirigir su conducta a partir de lo que pueda representar un costo o un beneficio para sus intereses. Por supuesto, cuando una persona se encuentra como habitante o visitante de un sector considerado como crítico y/o vulnerable por razones de inseguridad y su vida gira en torno a lo ilícito y a la supervivencia, las condiciones para delinquir serán más latentes y por ende, existirá una mayor tendencia a tomar la decisión de radicarse en ese lugar de manera definitiva (Rau \& Prosser, 2009). En buena medida, quien hace del delito una forma de vida o la única posibilidad de subsistencia ve en estos sectores su mejor y único proyecto.

Wacquant Loïc (2010), menciona que cuando se produce la exclusión o marginalización de un espacio o barrio que generalmente concentra una población de bajos recursos, difícilmente esta población no sucumbe a los intereses de las estructuras criminales, por lo que termina, en la mayoría de casos, siendo parte de ella o conviviendo bajo sus códigos y normas. ${ }^{4}$

La calle del Cartucho y la calle del Bronx en la ciudad de Bogotá, representan un clásico ejemplo de esta dinámica. En ellas se puso en evidencia la coexistencia de un conjunto de factores situacionales que representaron variables importantes para llegar a ese proceso de territorialización, por un lado a través de un individuo con unas necesidades básica insatisfechas o adicto a las drogas y, por otro, por la presencia de estructuras criminales al servicio del microtráfico que, aprovechando las necesidades de esta población, logró consolidar un territorio por fuera del control legal y del Estado.

En este contexto, el microtráfico o narcomenudeo representa uno de los fenómenos más relevantes a la hora de estudiar un proceso de territorialización de la inseguridad desde el individuo o la estructura criminal como tal. Si bien hoy en día gran parte de las ciudades

\footnotetext{
4 Para una ilustración estimulante sobre ghettos, leer la descripción de Wacquant, Loïc (2010). El diseño de la reclusión urbana en el siglo XXI.
} 
del mundo afrontan problemas de narcotráfico, existen territorios donde estas manifestaciones minimizan la capacidad de decisión de las personas y adquirieren una mayor significación, por el sistema de relaciones sociales, económicas y criminales que se generan alrededor de territorios o espacios específicos.

De tal manera que al hablar del microtráfico como parte de un sistema, se evidencia una realidad: la utilización de estructuras criminales para cerrar a nivel barrial, el círculo de distribución al por mayor del narcotráfico. Es decir, desde una mirada económica, el microtráfico representa el punto de contacto y regulación con los adictos, los consumidores, las ciudades y los barrios. Asimismo, por su importancia e impacto, el microtráfico también ayuda entender cómo en la mayoría de casos, quienes terminan siendo víctimas de las estructuras criminales y los intermediarios, son los habitantes del sector territorializado y, por supuesto, los consumidores.

La favela Rocinha, en Río de Janeiro, es otro caso emblemático frente a la aplicación práctica de esta teoría, si se tiene en cuenta el dominio de más de treinta años que han tenido las estructuras criminales, conformadas en su mayoría por jóvenes que transitan armados por sus calles para garantizar el flujo diario del microtráfico e impedir que las autoridades ingresen a la favela.

Como se evidencia en estos ejemplos, bajo las circunstancias de inseguridad, criminalidad y exclusión que presentan por lo general los habitantes de estos sectores, su margen de decisión, racionalidad y maniobrabilidad para salir de estos abismos delictivos es mínimo o quizás, nulo. De ahí que gran parte de esta población haya edificado voluntaria o involuntariamente unas condiciones de arraigo sobre estos territorios, optando por hacer de ellos su escenario natural de vida. ${ }^{5}$

\footnotetext{
5 "Estuve en el Cartucho inicialmente y luego en la calle del Bronx. ¿Por qué llegué allá? Primero porque sabía que era un lugar de tolerancia donde podía consumir droga sin que nadie me jodiera y las autoridades no molestan. Además, a nadie le importa si uno fuma o no, cada uno hace con su vida lo que quiere. Y tercero, como una vía de escape de la sociedad y del qué dirán cuando lo ven consumir a uno. Mi llegada allá se debe a información que me dieron unas personas de un centro de rehabilitación en el que estuve. Ellos me invitaron a
} 
Quien habita este tipo sectores es consciente de que mientras cumpla con las normas y códigos establecidos por las organizaciones criminales y/o por quienes detentan el poder, no correrán peligro alguno y aseguraran así su supervivencia. De tal manera que al realizar un delito por fuera de su zona de confort, pueden sobrevenir dos situaciones: ser aprehendidos en flagrancia por la autoridad competente (costos), lo que significaría unos beneficios totalmente nulos y negativos, o no ser aprehenndidos y lograr sus objetivos (beneficios).

El análisis costo-beneficio al tenor de la teoría de la elección racional, también puede ser valorado por ellos en otro sentido: asumen el riesgo de actuar por fuera de la zona (costo), pero con la tranquilidad de que, una vez logrado su objetivo, podrán refugiarse en la misma para comercializar el producto de su ilícito (beneficio). Adicionalmente, pueden consumir sustancias para calmar su adicción a las drogas (beneficio).

Ahora bien, una estructura criminal que ejerce su dominio y poder dentro y fuera de un sector territorializado por la inseguridad, identifica verdaderos escenarios monetarios y de poder en los nichos de inseguridad y criminalidad, cuyo análisis costo-beneficio se representa como un espacio bastante atractivo para ellos, en la medida que su actividad criminal la desarrollan a través de terceras personas, en zonas bajo su control, rigiéndose por sus códigos y con un riesgo mínimo de ser aprehendidos por las autoridades. En la mayoría de casos quienes tienene el control de estas zonas se aprovechan del estado de adicción a las drogas psicoactivas de los individuos que las

que fuera a echarnos unos "cosos" (bazuco) al cartucho y de paso antes conocía. A mí me daba miedo inicialmente, pero como iba con gente que conocía, eso se me paso. Llegamos y ellos conocían bien el sector, conocían personas del lugar y visitantes frecuentes del mismo. Me metí al "callejón de la muerte" (gancho amarillo), como era conocido, porque ahí a cada rato mataban gente y era la calle donde estaban todos los expendedores de droga. Pedí la droga que necesitaba (bazuco) y ahí me senté a consumir y a observar la dinámica del sector. Ahí se ve toda la miseria humana, la gente se pudre por enfermedades, desnutrición, droga, cerebros divagando, locos, etc. Inclusive tuve la oportunidad de ver el homicidio de varias personas. Imperaba la ley del más fuerte". (Luis Alberto Moreno, Comunicación personal, 24 de marzo de 2014). 
frecuentan o las habitan, motivo por el cual este tipo de estructuras están más interesadas en crear escenarios que faciliten el desarrollo de sus actividades al margen de la ley y por ende, de generar escenarios de "territorialización" (Felson, 1997).

La elección de permanecer o no en un sector crítico y/o vulnerable, así como acontece con cada persona individualmente considerada, dependerá exclusivamente de la organización criminal, en la medida en que es ella quien detenta el poder de decisión. Bajo esas circunstancias, las organizaciones criminales entran a jugar un papel importante en contextos de territorialización, si se tiene en cuenta que cuando estas o quienes detentan el poder al interior de las mismas, realizan un análisis costo-beneficio, generalmente optan por ingresar y apoderarse del barrio o de un sector específico de este, imponiendo sus reglas de juego como medio para la generación de un provecho económico, de respeto o de poder (Ávila, 2010).

La estructura criminal, antes de adoptar una decisión, evalúa si las condiciones que arroja el medio le son favorables o no para llevar a cabo su accionar delictivo; por ejemplo, estudian la baja presencia de policía en la zona, la probabilidad de lograr cierto grado de complicidad por parte de los habitantes del sector o quienes lo frecuentan, la aplicación laxa de la ley, el estado de corrupción de las autoridades que ejercen su labor preventiva o represiva en el sector, así como el grado de pobreza, desempleo y marginalidad social del territorio objetivo (Cohen \& Felson, 1979).

Finalmente, la segunda teoría objeto de estudio dentro de la dimensión subjetiva es la teoría de la "Actividad Rutinaria", propuesta por Lawrence Cohen y Marcus Felson (1979), la cual explica cómo los rasgos socio comportamentales repetitivos que suelen adoptar los habitantes o quienes frecuentan zonas críticas y/o vulnerables, constituyen un factor decisivo a la hora de generar arraigo o pertenencia entre estos y dichos lugares, hasta el punto de ver el delito, la pobreza, la exclusión, la marginalidad y la no satisfacción de sus necesidades básica, como algo normal y rutinario. 
Al confluir en un mismo lugar un objetivo conveniente, la ausencia de condiciones de seguridad y la existencia de un individuo motivado para la realización de actividades ilícitas, se reúnen los presupuestos necesarios para generar o consolidar territorios inseguros y, por ende, desarrollar un proceso de fijación permanente o temporal en el mismo (Secretaría de Seguridad Pública de México D.F, 2008).

Desde esta perspectiva, un barrio, una zona o una calle territorializada, representa un verdadero laboratorio de inseguridad, si se tiene en cuenta que alrededor del mismo convergen todas las condiciones rutinarias que facilitan "procesos de territorialización", vale decir: presencia de transgresores motivados (organizaciones criminales, habitantes de la calle, recicladores, población desplazada, adictos, consumidores esporádicos, etc), ausencia o aparición intermitente del Estado o sus autoridades y manifestaciones delictivas de todo orden.

Quienes habitan o frecuentan un sector territorializado, ven en la inseguridad, el delito y el crimen fenómenos normales propios de su diario vivir y de una práctica rutinaria. Estas personas terminan convirtiendo cada una de las actividades asociadas a la inseguridad, en una acción habitual, que dependiendo de la organización criminal o del individuo, darán curso a un proceso de permanencia o tránsito en el sector, por supuesto agravando o consolidando las condiciones de inseguridad del mismo (Clarke \& Felson, 1979).

El interés de un individuo u organización criminal por permanecer o abandonar un territorio con estas características, lleva a que estos adecuen o exterioricen su comportamiento conforme se desarrolle la dinámica de su entorno o la rutina de su modus vivendi, sin que ello signifique que pierdan autonomía a la hora de adoptar uno u otro comportamiento. De ahí que siga siendo este, como sujeto el que decide continuar o no dentro de la zona o sector territorializado.

Ariel Ávila señala en el libro Mercados de Criminalidad en Bogotá (2010), que la permanencia de la inseguridad y la criminalidad en un territorio, y su desarrollo, actividad y expansión, terminan por convertirse en fenómenos rutinarios y normales para quienes habitan el lugar. Inclu- 
sive mientras todos se beneficien de esos escenarios ilícitos (personasestructuras criminales) y los riesgos sean mínimos, permanecerán en el sector. Cuando el Estado tiene una presencia intermitente y débil o decide realizar intervenciones represivas fugaces, la población flotante y las estructuras criminales "mutarán” hacia otra zona crítica y/o vulnerable, y fijarán ahí sus nuevos intereses.

En esas condiciones, una zona territorializada por la inseguridad es un escenario de oportunidades para la criminalidad. Por ejemplo, Secondigliano, localizado en la ciudad de Nápoles, es considerado uno de los barrios más peligrosos, ${ }^{6}$ por el control total que ejerce una de las mafias más influyentes y extensas del mundo: ${ }^{7}$ La Camorra. ${ }^{8}$ Esta estructura criminal ligada al narcotráfico mundial también controla barrios completos, como "Sanitá", con clanes como Di Lauro y Sarno, ${ }^{9}$ a tal punto que son ellos quienes deciden que se hace en "Secondigliano", quien entra y quién no. ${ }^{10}$ Sus habitantes aprendieron a convivir con ella y con sus expresiones criminales como algo común y rutinario, si se tiene en cuenta que deben optar por pertenecer a ella o guardar silencio de todo aquello que ven o escuchan, so pena de ser torturados, desterrados o asesinados.

\footnotetext{
6 Alcanzó en los años noventa el récord mundial de homicidios por habitante.

7 La Camorra tiene fuertes vínculos con España, ya que sus clanes actúan y trabajan en ella desde los años 80 , y además, esta sirve de escondite sin interrumpir sus actividades, para llevar droga, especialmente cocaína y para lavar dinero comprando todo tipo de inmuebles, por ejemplo relacionados al negocio del turismo y las discotecas. Se especula que pretenden controlar militarmente el territorio español y que el país está creciendo gracias al dinero sucio de esta mafia, pero también ha reinvertido las utilidades del negocio ilícito en Italia, en apartamentos, hoteles y tiendas. (Periódico Diagonal Global, 2007).

8 "Organización criminal compuesta por 2.000 familias en lucha permanente por un poder, que facturaba a 200412 millones y medio de euros al año, de los que siete provienen del tráfico de drogas. La Camorra que extiende su poder en gran parte de Nápoles es responsable a 2004 de casi 4.000 muertos en 30 años". (Periódico Diagonal Global, 2007).

9 "En la ciudad los mafiosos denominan como El Sistema a las distintas zonas de influencia de los clanes. Cada sistema es un clan, que establece una complicada estructura de lealtades y protecciones, junto con castigos muchas veces mortales". (Periódico Clarín, 2006).

10 "Las personas cuando van en moto no llevan casco a pesar de estar por ley obligados, debido a que la mafia quiere ver las caras de la gente que circula en moto con el objeto de comprobar si son policías o mafiosos de otros clanes rivales". (Periódico Clarín, 2006).
} 
Secondigliano simboliza lo que se ha denominado como "territorialización de la inseguridad", solo que para este caso, existe un proceso más sofisticado y la participación de una verdadera estructura criminal, lo que pone en evidencia, cuán difícil puede ser para las autoridades intentar revertir la situación, una vez el mismo se ha instalado y consolidado en la forma de vida de sus habitantes.

\section{Teorías explicativas de la territorialización, a partir del territorio y el entorno}

Este conjunto de teorías hace parte de la dimensión objetiva de nuestra aproximación teórica y busca explicar la aparición y/o consolidación de procesos de "territorialización", a partir del territorio y el entorno. El primero entendido como el espacio físico y sus elementos geográficos y urbanísticos; el segundo, como aquellos factores inductores y/o facilitadores de inseguridad desde el punto de vista histórico, económico, social, político y de mercado, entre otros, que condicionan, facilitan o contribuyen a consolidar procesos de "territorialización".

Los ejemplos prácticos frente a este escenario son innumerables, pues no se puede ocultar la innegable conexión entre espacio geográfico e inseguridad. La mayor parte de los delitos ocurren en áreas concretas y son ejecutados por personas que llegan o van a determinado lugar; en esa medida, la criminalidad y la inseguridad como fenómenos sociales tienen un importante sustento explicativo, a partir del escenario geográfico donde se presentan. Esto permite identificar en la inseguridad cierta lógica espacial, que brinda una explicación más allá de la oportunidad y el azar.

Si bien en este contexto también se encuentra un importante universo de posiciones teóricas alrededor de la relación seguridad/inseguridad, nuestra disertación se ocupa principalmente de la teoría del Patrón Delictivo, la teoría de Ventanas Rotas y la teoría de La Desorganización Social, por considerar que sus presupuestos conceptuales y prácticos, reúnen elementos importantes a la hora de explicar el objeto de este escrito. 
La teoría del Patrón Delictivo plantea que los delitos no ocurren al azar y que, por el contrario, existen sectores, barrios o zonas en los que se producen muchos más delitos que en otros, es decir, parte de unos patrones o tendencias que son traducidos por los transgresores como oportunidades para delinquir (Vozmediano, 2010). ${ }^{11} \mathrm{Al}$ respecto, Pat Brantingham y Paul J. Brantingham (1984, 1993, 2008) crearon un modelo teórico que ayuda a entender la configuración y distribución geográfica del delito, así como la identificación de patrones de inseguridad en escenarios urbanos territorializados, como herramienta para la construcción de mapas delictivos ${ }^{12}$ y la identificación de factores que coadyuvan o consolidan este tipo de escenarios.

Este modelo propone el estudio del delito mediante niveles de segregación en tiempo y espacio, como un mecanismo para identificar patrones de inseguridad. Por ejemplo, a nivel internacional y nivel nacional, en áreas más pequeñas que van desde las regiones de los estados a los condados, a las ciudades y en los planos detallados dentro de una ciudad en particular; incluso hasta el bloque de la calle o el nivel de dirección individual. El análisis temporal puede abarcar años, meses, días, horas, minutos o segundos.

En Colombia, tanto en la calle del Cartucho como en la calle del Bronx, se mueve el microtráfico, el negocio ilícito de tragamonedas, licor de contrabando, licor adulterado, tráfico de armas, sicariato, prostitución, extorsión, hurto, venta y compra de artículos robados, ventas de cheques robados, concierto para delinquir:

Para vueltas grandes todo es con la gente dura del sector. Aunque hay vueltas que se las proponen a uno directamente. Una

\footnotetext{
11 De acuerdo con la teoría una vez se tengan identificados los patrones (calles, parques, escuelas) del crimen se puede implementar estrategias dirigidas a dos finalidades: reducir índices delictivos y que los residentes conozcan cómo se encuentra la criminalidad en su zona (el modus operandi).

12 También ayuda a definir un problema específico, apiñar los patrones del victimario y los de ofensas, para intentar encontrar los nodos, trayectorias y bordes e identificar en qué momento los victimarios están ausentes y dónde se congregan (puntos críticos), e invita a pensar sobre las razones de ello (Vozmediano et al., 2010).
} 
vez me llegó un tipo y me dijo que me daba seis millones por ir a bajar a un man, que me daba una parte al inicio y luego la otra. También se mueve el negocio de la escopolamina. Todas las vueltas se mueven así. Otra vez un man me dijo que iban a poner un centro de rehabilitación y luego me enteré de que era una banda de atracadores. Uno desde abajo ve quienes son los duros, uno se los cruza y así como fácilmente puede recibir una moneda, puede recibir un balazo. Ellos prácticamente llegaban a hacer cuentas con su equipo de seguridad con armas largas. La prostitución se mueve alrededor del consumo. Hay menores de edad. La misma sustancia doblega al ser humano (Luis Alberto Moreno, Comunicación personal, 24 de marzo de 2014).

La aplicación a un sector territorializado de la teoría del Patrón Delictivo y lo consignado por Pat y Paul Brantingham, permite evidenciar que frente a la concurrencia de patrones de inseguridad, difícilmente un individuo deja al azar la selección del lugar para delinquir, esencialmente, porque éste ya conoce las tendencias criminales de la zona y cuál es el momento adecuado para actuar o no en determinada forma. Bajo estas premisas, un sector urbano que presente patrones críticos y/o vulnerables, será a futuro un serio candidato a vivir un proceso de territorialización.

Inclusive en el sentir de quienes habitan o frecuentan la zona, existe un territorio límite para delinquir, en tanto hacerlo por fuera de ella, no solo amplía la posibilidad de no lograr el objetivo, sino de terminar mal. En últimas lo que se presenta es la existencia de una zona, barrio o territorio de confort delictivo, del cual no se quiere apartar quien está en el terreno de lo ilegal, a menos que le genere algún peligro.

De esta manera, un individuo que habita o frecuenta un entorno complaciente con toda forma delictiva, tendrá frente a él las siguientes motivaciones: analizará qué le ofrece el ambiente, por ejemplo, si existe facilidad o no para adquirir o consumir drogas; también revisará si existe oportunidad para comercializar o no el producto de un hurto o atraco, la preparación y/o la consumación de un delito, e inclusive, ejecutar un homicidio al interior de la zona sin temor a ser 
aprehendido por las autoridades. En un sector con patrones de seguridad elevados y presencia permanente de autoridad, las motivaciones no tendrán la misma secuencia analítica, en la medida en que estas variables le restan motivación a su accionar, le impiden identificar un objetivo concreto y, por ende, una mayor posibilidad de éxito.

Villa del Bajo Flores, también conocido como 1-11-14, es el barrio marginal más poblado ${ }^{13}$ y peligroso de Buenos Aires. ${ }^{14}$ Los patrones que le hacen merecedor de tal calificativo son su pobreza extrema, ${ }^{15}$ su tasa de homicidios y las disputas territoriales entre pequeños narcos y bandas criminales. En este escenario sobran las motivaciones que tendrá una persona para delinquir, teniendo en cuenta que las personas conviven con el delito y hacen de este su modo de vida. Esta situación ha hecho que las autoridades no solo no sean bienvenidas, sino que eviten entrar a sus calles. Curiosamente quienes se pugnan el control de varias zonas del barrio son inmigrantes de Perú (algunos ex guerrilleros de Sendero Luminoso), Paraguay y Bolivia. Ellos no solo buscan un control territorial, sino liderar el comercio de droga. ${ }^{16}$

13 "Resultado de la unión de tres asentamientos ilegales (el 1, el 11 y el 14). Según estadísticas oficiales, 50.000 personas, entre ellos de origen extranjero, viven en 30 manzanas, aunque varias ONG estiman que este número puede ser mayor y llegar a los 80.000 habitantes. En concordancia, el último censo nacional y otros relevamientos realizados en la ciudad de Buenos Aires, permite observar que mientras el total de la población de la ciudad de Buenos Aires ha crecido solo un 4.1\% entre el período intercensal (2001-2010), algunas villas han crecido más de un 100\% y otras rondan en porcentajes de crecimiento cercano. Cada diez años, aproximadamente, las villas duplican su población”. (El Espectador, 2013; Jauri, 2010, p.3).

14 "Se dice que el barrio de Flores es el más inseguro de Buenos Aires, pero se sabe bien que lo es por su cercanía con una de las villas más peligrosas de la ciudad. En sus márgenes, La villa 1-11-14 se convierte en el principal foco del crimen de la capital argentina" (Procuraduria General de la Naciòn, 2010, p.17). Datos de la Procuración General de la Nación reseñan que "en 2010 la tasa de homicidios en este sector fue de 12,7 por cada 100.000 habitantes, mientras que en el resto de los barrios el índice no supera los tres asesinatos por cada 100.000 personas" (Procuraduría General de la Nación, 2010, p. 22).

15 Edificaciones precarias de madera, lata y ladrillo acompañadas de calles y callejones estrechos; es uno de los pocos barrios marginales con servicio de electricidad y agua.

16 El narco lleva la droga para que sus transas vendan (red de pequeños expendedores, dealers o transas, como se les conoce en Argentina), mientras los campaneros dominan los distintos recovecos del barrio. 
En esa misma dinámica, Tepito, un barrio popular de la Ciudad de México, perteneciente a la delegación Cuauhtémoc, conocido como Barrio Bravo, presenta como patrón central de inseguridad el comercio informal, espacio desde el cual se aglutinan delitos como el microtráfico, la venta de piratería-contrabando y la venta de productos hurtados. ${ }^{17}$ Finalmente, el South Bronx o Bronx Sur, situado al noroeste del Estado de Nueva York, es epicentro de delincuencia (atracos y homicidios), tráfico de drogas, armas y comunidad de drogadictos (Contreras, 2014). El proceso de territorialización que se presenta en la zona, obedece principalmente a seis factores: la crisis económica de los años treinta, la presencia de estructuras criminales que controlan al microtráfico, el desempleo y la pobreza, la falta de inversión y, por ende, la degradación de los sectores más vulnerables y/o críticos, el deterioro y abandono de edificios y la estigmatización del sector por parte de las autoridades y los medios de comunicación.

Como lo refiere Laura Vozmediano ${ }^{18}$ en su libro Criminología Ambiental: La Ciudad como Escenario del Crimen (2010), frente a los problemas de inseguridad derivados de la criminalidad urbana, el territorio y los patrones que alrededor del mismo se generan, constituyen un importante universo de estudio, en la medida en que permiten comprender sus tendencias ilícitas y la forma de combatirlas.

Otra teoría importante frente al universo en estudio, es la teoría de las Ventanas Rotas, difundida por George Kelling y James Wilson (1982). Personalmente, constituye uno de los principales soportes teóricos explicativos frente a un proceso de territorialización. A través de sus

\footnotetext{
17 Según CNN $(2010,2012)$, Tepito es la principal fuente abastecedora de mercancía ilegal (ropa, discos, películas, libros, cosméticos y bisutería), frecuentemente importados de China, incluso bases de datos confidenciales. "En 1901, ya existían los llamados "baratillos", basados en trueques de prendas usadas. Desde entonces, ha sido el "ropero de los pobres" para los habitantes de la zona metropolitana. Es pertinente mencionar que entre los mitos que envuelven a esta meca del comercio ilegal, sobresale el narcoculto a las armas y una doctrina con especial devoción a la Santa Muerte. La veneración cobró mayor auge luego de decomisos a los principales capos del narcotráfico de pistolas y revólveres con cachas de marfil, incrustaciones de oro, diamantes y zafiros" (Nueva Era, 2012, p.19).

18 Profesora de la Universidad del País Vasco en Psicología Criminal y Criminología Ambiental
} 
postulados, se busca explicar la dinámica que presenta un proceso de esta índole, bajo la relación causal existente entre seguridad/inseguridad y fenómenos como el desorden, la indiferencia estatal y ciudadana, la decadencia urbana y el miedo.

Los criminólogos James Wilson y George Kelling (1982) encontraron que el delito, en cualquier centro urbano, "era mayor en las zonas donde prevalecía el descuido, la suciedad y el maltrato a los bienes públicos" (p.33), por lo que resultaba coherente considerar que el crimen y la inseguridad era el resultado inevitable del desorden (Secretaría de Seguridad Pública de México, 2008, p.10). ${ }^{19}$ En otras palabras, el desorden y el deterioro tenían efectos sobre la delincuencia ${ }^{20}$, trayendo consigo lo que se conoce como el "efecto cadena" (Martin \& Ceballos, 2004, p. 159; Vargas \& García, 2007, p. 261).

La teoría utiliza el término de Ventanas Rotas como metáfora explicativa de la relación que puede llegar a existir entre el delito, el miedo, el desorden, el descuido y el papel que juegan las autoridades frente a la atención oportuna o no de aquellas situaciones, que si bien pueden comenzar como una manifestación minina de desorden o alteración, de no tener una reacción inmediata, pueden conllevar a la generación de verdaderos escenarios de inseguridad.

19 Olavarría, Tocornal, Manzano y Fruhling (2008) basados en los aportes de Sampson (2002) indican que "los signos físicos de desorden en espacios públicos son señal del desinterés de residentes por apropiarse y cuidar de su entorno. Ello invita a terceros residentes transitorios o de paso a cometer delitos en tales lugares. Si los residentes tuviesen voluntad para intervenir el desorden y el deterioro en nombre del bien común, ejerciendo una especie de control y cohesión social, se evitaría el efecto cadena que señala la teoría. De que se dé depende de la confianza mutua y expectativas compartidas entre los residentes de la zona. Es improbable que se dé la intervención comunitaria cuando las reglas no son claras y la gente desconfía entre sî" (p. 6).

20 "Contrario a lo anterior los estudios de Sampson y Raudenbush han demostrado que el vínculo entre desorden físico y crimen no es tan fuerte, y más bien se ha detectado que el desorden físico puede ser explicado por factores similares a los causantes del delito (Sampson, 2002). Es decir, el desorden físico es solo una señal más del problema, no su causa (...). Otros estudios han planteado que las señales de desorden físico reflejan cierto deterioro de los barrios y el fracaso de las instituciones, públicas y privadas, para abordar estos problemas, lo que a la larga se traduce en disminución de inversión y en la expulsión de los residentes" (Redondo, 2018, p. 65). 
Una ventana rota no reparada transmite un mensaje de descuido y desinterés, que puede llevar a los transeúntes a romper otras ventanas del mismo edificio. En unos días, el edificio podría llenarse de pintas y grafitis, y poco después, su acera convertirse en un basurero público o en un sector invadido por criminales.

Bajo ese entendido, y a la luz de esta teoría, cuando se habla de un escenario territorializado por la inseguridad y la criminalidad, se exhibe un pasaje urbano donde no existen controles estatales, ni mucho menos de la comunidad. Al no existir estos controles, en el imaginario de las personas se presentan dos situaciones: la primera en relación con la libertad para delinquir sin problema alguno, y la segunda relacionada con el temor que genera el sector, no solo para quienes lo habitan o frecuentan, sino para aquellas personas ajenas al mismo, pero que indirectamente conocen de él a través de los medios masivos de comunicación, conllevando esta situación a su estigmatización y a un incremento en el proceso de marginalización social. De tal manera que un sector íntimamente ligado al desorden y el descuido es vulnerable a la invasión de estructuras criminales y la generación de todo tipo de formas delictivas.

Sousa y Kelling (2004), afirman que las desigualdades estructurales y sociales rompen las ventanas del orden y representan situaciones caóticas, aún en escenarios controlados por el Estado. Por eso, la teoría de las Ventanas Rotas invita a combatir cualquier situación que atraiga al delito, que infunda temor dentro de la comunidad y que imposibilite acciones de carácter preventivo y represivo, pues de mantenerse la indiferencia, ese lugar seguramente se transformará en el punto de encuentro de pandilleros, atracadores, adictos y por supuesto, organizaciones criminales.

Sánchez, Espinoza y Rivas (2003) lo ratifican:

[...] la tolerancia de desórdenes menores como basuras en las calles, obstrucción de vías, vagos, personas bebiendo en lugares públicos, mendigos y prostitución, generan un ambiente propicio para el crimen y la inseguridad. La tolerancia de desórdenes 
menores es una señal de falta de control y represión de comportamientos delincuenciales, que generan un ambiente propicio para criminales en potencia. Al igual que una ventana rota que se deja sin reparar hace las veces de invitación a romper otras ventanas del mismo edificio, la tolerancia progresiva de desórdenes menores y comportamientos que infringen las normas de una comunidad, hacen de ella una comunidad vulnerable frente al crimen (pp. 32-33).

Finalmente se tiene la teoría de la Desorganización Social formulada por la Escuela de Chicago.

En los años cuarenta, Clifford Shaw y Henry McKay (2012) efectuaron algunos experimentos encaminados a conocer y analizar el comportamiento criminal en la ciudad de Chicago. El resultado de esas investigaciones pretendía explicar cómo se originan y consolidan los núcleos delictivos a partir de la "desorganización social" que se genera, entre otros, por las características de una zona, lugar o sector, y por el desarrollo urbano que se refleja a través del comportamiento de los habitantes de la calle, las prostitutas, los adictos y los miembros de pandillas (Escobar \& Gipsy, 2012).

Para Bursik y Grasmick (1995), “desorganización social” es la violación de un acuerdo tácito sobre las normas de comportamiento públi$\operatorname{co}^{21}[\ldots]$, y que tiene efectos sobre la acción colectiva, la delincuencia y las tasas de criminalidad en espacios urbanos". ${ }^{22}$ Cuando la acción colectiva, entendida esta como la actuación de la institucionalidad y

21 "Los residentes de una comunidad pueden llegar a acuerdos tácitos o explícitos con facinerosos delincuentes, a fin de mantener un mínimo de paz y orden cuando estos últimos cooptan redes sociales locales" (Escobar, 2012).

22 La variabilidad en el índice de homicidios cometidos por cada 100.000 habitantes en Colombia (ascensos y descensos) ha sido permanente. "Durante muchos años, investigadores colombianos atribuyeron estos niveles de violencia al conflicto armado interno en las zonas rurales y a la violencia interpersonal en áreas urbanas. Sin embargo, un informe del Banco Mundial (1999) demostró que durante los años 90 solo el 20 por ciento de los homicidios estaban relacionados al conflicto interno. Y, en cambio, la combinación de flagelos económicos y sociales (pobreza, desigualdad, rápido crecimiento urbano, falta de oportunidades educacionales y de empleo, disrupción familiar y precipitadores situacionales tales como 
la comunidad, la generación de valores comunes y el tejido social es precaria o nula, difícilmente podrán evitarse escenarios "territorializados" por la inseguridad y la criminalidad y lo que terminará imponiéndose es la acción colectiva, pero de las organizaciones criminales.

Un sector puede llegar a estar en poder de organizaciones criminales y de microtráfico, a razón de que el nivel de desorganización social acumulado por años, ha sido superior y mucho más visible que la acción colectiva y el nivel de compromiso comunitario de trabajar en equipo para ejercer control sobre la conducta de quienes exhibían incivilidad.

Los sociólogos Shaw y McKay concluyen sobre el particular: "la criminalidad tiene base alrededor de un barrio específico, sin importar quién viva en él en determinado momento. Una vez que la criminalidad se convierte en parte de la cultura de la zona, se transforma en una tradición que se comunica de generación en generación. Por lo tanto es el lugar y no la gente lo que importa".

Precisamente, la calle del Cartucho fue un sector de la capital colombiana habitado en su momento por un universo de personajes, muchos de ellos reducto de la clase marginal asociada al reciclaje, la droga, el crimen, la prostitución, el tráfico de armas, el sicariato, los homicidios y, por supuesto, la pobreza. Tal fue la transformación del sector, que su dinámica habitacional y el bajo costo permitió que mucha gente desplazada de otros lugares o consumida por el vicio viera en la zona una salida a sus problemas, o lo que es más grave, un escenario propicio para delinquir sin ser aprehendido o detectado por las autoridades.

Inclusive hay quienes presentan frente al contexto de inseguridad y criminalidad que vivía el Cartucho, toda una estructura al servicio del delito:

el fácil acceso al alcohol, drogas y armas de fuego) eran responsables del restante 80 por ciento de homicidios" (Periodico El Tiempo, 2011, p. 12). 


\begin{abstract}
"La violencia en este sector permitía evidenciar dos componentes esenciales: relacionaba elementos legales e ilegales de la sociedad (como fue demostrado por Stannow y Rojas en el caso de la "limpieza social") dentro del comercio de drogas y ayudaba a mantener el control de la zona mediante una estricta jerarquización” (Góngora \& Suárez, 2008, p. 123).
\end{abstract}

Desde otro escenario, la favela Rocinha en Río de Janeiro, una zona llena de laberintos y de casas inaccesibles, fue durante muchos años el refugio de todo tipo de delincuentes. Inclusive su proceso de territorialización llegó a tal punto, que las estructuras criminales que habitaban el sector tenían mejor armamento que el que disponía el ejército brasileño (Periódico O Globo, 2013). ${ }^{23}$ La permisividad y complacencia que existió durante muchos años por parte de las autoridades y el Gobierno de turno, llevó a pensar que era una utopía su proceso de intervención y pacificación. Aquí los narcotraficantes y las estructuras criminales impusieron durante décadas la política del miedo y del terror, pues se estaba en un territorio donde lo principal era subsistir en medio de la inseguridad, la pobreza, la marginalidad y la exclusión social. Era más fácil y rentable para cualquier habitante de la favela adquirir un arma de fuego, que el mismo sustento diario (Folha de São Paulo, 2011).

Además, las características físico-espaciales de las favelas hicieron que las casas fueran construidas en materiales de baja calidad o simplemente se organizaran en "cambuches" en las laderas de las montañas. La Rocinha "era un entorno de marginalidad, violencia,

\footnotetext{
23 "La exitosa ocupación de las favelas de Rocinha, Vidigal y Chácara do Céu, incrustadas en los cerros que separan tres de los barrios más pudientes de Río de Janeiro (Gávea, Leblon y Sao Conrado) ha contado con la escenografía propia de un Estado de guerra, aunque no haya sido necesario dar un solo tiro. Pasadas las cuatro de la mañana, unidades de élite de la Policía Militar, Civil y Federal penetraron en las tres comunidades por diferentes accesos apoyadas por tanques y helicópteros de combate. Desde primera hora de la madrugada, tiradores de élite se encontraban apostados en diversos puntos privilegiados de los cerros. El grueso de la operación se produjo de noche y con el máximo sigilo, solo quebrado por el estruendo de los helicópteros al realizar vuelos rasantes sobre las casas y por la evolución de los tanques en diferentes zonas de las favelas" (Periódico Extra, 2013).
} 
drogas y pobreza. En definitiva, era el peor lugar para que nazca una persona" (Folha de São Paulo, 2011, p. 5).

\section{Conclusiones}

- El fenómeno de la territorialización de la inseguridad ciudadana debe ser concebido como una entidad multicausal y, por tanto, diversa, en la medida en que confluyen diversos factores que deben ser analizados de manera integral, particularmente, cuando dichas variables adquirieren un estatus de crónicas. No obstante su multicausalidad, las políticas públicas no siempre van de la mano con ella; por el contrario, se adopta la misma estrategia de gobierno en gobierno, aún a pesar de su fracaso.

Bajo esa perspectiva, no puede perderse de vista que al acumularse en un territorio una serie de patologías y factores de riesgo, tienden a perpetuarse en el tiempo espacios de inseguridad difícilmente modificables, si no se adoptan medidas integrales a tiempo. Dicho de otra manera, al conformarse en la ciudad sectores centrales o periféricos en condiciones de alta vulnerabilidad social, económica, política, geográfica y laboral, se irán consolidando, más que en otros lugares de la ciudad, prácticas delictivas complejas y no muy fáciles de erradicar.

Teorías como la elección racional, la actividad rutinaria, el patrón delictivo y las ventanas rotas dejan en evidencia cómo un proceso de territorialización encuentra significancia en el comportamiento individual delictivo, en el actuar de una estructura criminal o en las condiciones que ofrece un entorno o territorio, como fuentes de criminalidad e inseguridad. En consecuencia, un escenario crítico y/o vulnerable "capturado" por la inseguridad, será de dominio exclusivo del individuo o estructura criminal, en tanto el Estado no le ofrezca otras alternativas de vida.

- El Estado debe concentrarse en el individuo y la satisfacción de sus necesidades mínimas, como una forma de atacar la inseguridad en ciertos territorios; si el sujeto obtiene una respuesta positiva 
de la institucionalidad, disminuyen las posibilidades de encausar su comportamiento individual hacía el delito. De este modo, más allá de caer en el error de adoptar medidas represivas, mediáticas y coyunturales, producto más de la percepción ciudadana de miedo y de la sensación de impotencia de los gobiernos locales, se debe optar por una solución definitiva a las dinámicas de territorialización, a partir de dos presupuestos: individuo y territorio.

Con lo anterior no se pretende concluir que una ciudad ideal es aquella donde la erradicación de la inseguridad es total, por cuanto esto resultaría utópico, habida cuenta de que la misma está compuesta por una serie de fenómenos y factores ligados a la existencia misma del Estado y de la sociedad; lo que sí debe buscarse es controlar los factores negativos, mediante la implementación de políticas, programas, proyectos y estrategias frontales y focalizados contra la territorialización.

- No es lo mismo destinar medidas para el universo de la seguridad urbana, que para la seguridad de un sector específico y vulnerable. ${ }^{24}$ Lo anterior implica necesariamente que el Estado y las autoridades locales, no pueden seguir bajo una respuesta institucional contra la inseguridad, por lo general, ex post, represiva y no preventiva de escenarios urbanos capturados por patologías y territorialización. Las estrategias relámpago, represivas y mediáticas jamás representaran un resultado efectivo contra fenómenos de territorialización de la inseguridad, ya que estas no solo no solucionan el problema de inseguridad y criminalidad que se irradia desde estas zonas, sino que desplazan las prácticas delictivas hacia otros entornos

24 Llorente y Rivas (2005) consideran que "el caso de Bogotá es ilustrativo del desarrollo de una política de seguridad ciudadana donde se combinan estrategias de diversa índole como el control a factores de riesgo como el consumo de alcohol y el porte de armas de fuego, el fortalecimiento de la capacidad de la policía en la ciudad, iniciativas de cambio cultural que propenden por el respeto a la vida y por la autorregulación de las conductas ciudadanas e intervenciones del espacio urbano deteriorado, entre otras. Esta combinación de estrategias y los resultados en términos de reducción de la criminalidad y de la sensación de inseguridad, hacen que esta experiencia sea un buen ejemplo de las diversas posibilidades que existen para enfrentar fenómenos de crimen urbano y, particularmente, de violencia” (p. 4). 
urbanos, lo que trae consigo una reorganización de la actividad, una transformación de las modalidades de criminalidad y una invisibilización de estos nuevos contextos de inseguridad.

- Para romper el círculo vicioso de intervenciones fallidas o sin trascendencia y por ende, de ciclos repetitivos de inseguridad y criminalidad, es importante lograr que las autoridades asuman su rol en la prevención de la territorialización de la inseguridad y la criminalidad. $^{25}$

\section{Consideraciones finales}

- Bajo esta misma óptica, es necesario que asuman la reconversión de los sectores territorializados por la inseguridad, así como la rehabilitación social de la población involucrada. Como se evidencia, tan solo en estos ejemplos citados en el artículo, bajo las circunstancias de inseguridad, criminalidad y exclusión que presentan por lo general los habitantes de un sector territorializado, su margen de decisión, racionalidad y maniobrabilidad para salir de estos abismos delictivos es mínimo o quizás, nulo. De ahí que gran parte de esta población ha edificado voluntaria o involuntariamente unas condiciones de arraigo sobre estos territorios, optando por hacer de ellos su proyecto de vida.

- Plantear un ataque frontal y represivo a un sector "territorializado" no es la estrategia más adecuada. Las organizaciones criminales articulan muchas zonas de una ciudad y estas a su vez se comportan como un sistema. Por eso, mientras las autoridades se dedican a golpear pequeños focos de inseguridad, los fenómenos

\footnotetext{
25 Dammert (2007), advierte que "si bien, en términos generales, los gobiernos locales enfrentan importantes limitaciones por su competencia y funciones respecto al nivel nacional para el desarrollo de estrategias de control, ocurre lo contrario con la prevención”, (...). El Gobierno Local es el actor preventivo por excelencia, porque es el único que puede articular las medidas orientadas a mejorar la violencia urbana, seguridad ciudadana y políticas públicas enfocadas a la calidad de vida urbana (iluminación, espacios públicos, transporte, empleo) y a aquellas directamente vinculadas a la criminalidad (prevención del consumo de drogas y alcohol y violencia doméstica)".
} 
delictivos que se liberen de dichos sectores quedarán absorbidos por los demás puntos críticos y/o vulnerables de la ciudad.

- El microtráfico y las estructuras criminales no desaparecerán porque un sector territorializado por la inseguridad sea intervenido, pues estos serán absorbidos por otros escenarios territorializados y recuperarán nuevamente el espacio perdido, si las autoridades no actúan de manera integral y focalizada. Por ello, pensar en acabar con escenarios donde hay muchos adictos no es una tarea fácil, al contrario, si se logra que estos barrios o zonas pierdan su status de "territorializados", se volverán entonces más callejeros, se incentivará la venta al menudeo, por lo que los expendedores se moverán con dosis pequeñas que no los comprometan judicialmente y, al final, persistirán los aspectos esenciales de la distribución. En esa medida, más que erradicar el microtráfico, el trabajo debería concentrarse en atacar las organizaciones criminales que lo sostienen y en generar una política integral y focalizada para con los habitantes del sector y quienes por razón del microtráfico y su adicción lo frecuentaban.

\section{Referencias}

Ávila A., \& Pérez B. (2010). Mercados de criminalidad en Bogotá. Bogotá: Corporación Nuevo Arco Iris, Editorial Linotipia Bolívar.

Banco Interamericano de Desarrollo - BID. Desarrollo y evaluación de programas de seguridad ciudadana en América Latina (2012). Reino Unido. Recuperado de http://cambridge-ebp.net/wp-content/ uploads/2014/02/espanolIADBProtocol.pdf

Boletín de la Red de Información de las Naciones Unidas sobre Justicia Penal - UNCJIN, Vol.2, No.3, 1994/95. Recuperado de http://www. iidh.ed.cr/comunidades/seguridad/docs/seg_docdocumrel/la $\% 20$ prevencion $\% 20 \mathrm{de} \% 201 \mathrm{l} \% 20$ violencia $\% 20$ urbana-piter-2005.pdf

Cities Alliance (2001). Mejoramiento de asentamientos precarios. Rio de Janeiro - Brasil. UN-HABITAT. Recuperado de https://books. google.com.co/books?id=jdxqFQyjgOYC\&pg=PA8\&lpg=PA8\&d $\mathrm{q}=$ desarrollo + urbanistico + Cities + Alliance $+2001 \&$ source $=$ bl\&ots $=$ KXLJGe1LIq\&sig=Crk_CjeHtfCbPvjmyj6VIDE7vYs\&hl=es\&s 
$\mathrm{a}=\mathrm{X} \& \mathrm{ved}=0 \mathrm{ahUKEwizscSVnqnOAhWLLMAKHXIyDX}$ XQ6AE IMDAD\#v=onepage\&q=desarrollo $\% 20$ urbanistico $\% 20$ Cities $\% 20$ Alliance $\% 202001 \& \mathrm{f}=$ false

Centro de Estudios de Seguridad Ciudadana - CESC (2009). Violencia en barrios críticos. Chile. RIL Editores. Recuperado de http://www.cesc. uchile.cl/publicaciones/violencia_en_barrios_criticos_lilian_manzano.pdf

Cohen, L. E. \& Felson, M. (1979). Social change and crime rate trends: a routine activity approach. American Sociological Review, 44(2), 588- 608.

Clarke, R. (1997). The Theory of Crime Prevention Through Environmental Design. Recuperado de www.e-doca.net

Dammert, L. (2007). Seguridad pública en América Latina: ¿qué pueden hacer los gobiernos locales? Nueva Sociedad (212), Recuperado de http://www.nuso.org/upload/articulos/3480_1.pdf

Gizewski, P., \& Horner-Dixon, T. (1995). Urban Growth and Violence: Will the Future Resemble the Past. Recuperado de http://www.homerdixon. com/1995/06/01/urban-growth-aand-violence-will-the-futureresemble-the-past/

Gómez, J. (2006) Barrios desfavorecidos: diagnóstico de la situación española. V Informe FUHEM de políticas sociales. Recuperado de http:/ / www.fuhem.es/media/cdv/file/biblioteca/Cohesi $\%$ C3\%B3n $\% 20$ Social/ALGUACIL\%20G\%C3\%96MEZ,\%20Julio,\%20Barrios\%20 desfavorecidos.pdf

Góngora, A. \& Suárez, C. (2008). Por una Bogotá sin mugre: violencia, vida y muerte en la cloaca urbana. Universitas Humanistica, 2. Recuperado de http://www.javeriana.edu.co/Facultades/C_Sociales/ universitas/66/05gongora.pdf.

Jauri, N. (2010). Las villas de la ciudad de Buenos Aires: una historia de promesas incumplidas. Recuperado de http://perio.unlp.edu.ar/ojs/index.php/ question/article/viewFile/565/856

Llorente, M. \& Rivas, A. (2005). Prevención del crimen y la violencia en zonas urbanas de América Latina. Estudio de caso: La caida del crimen en Bogotá: una década de políticas de seguridad ciudadana. Departamento de Finanzas, Sector Privado e Infraestructura para América Latina del Banco Mundial. Recuperado de http://www.cca.org.mx/funcionarios/cursos/ap092/ modulo1/bogota.pdf 
Massey D. - Denton N. (1993). American Apartheid. Harvard University. Recuperado de http:/ / socrates.berkeley.edu/ tochtli/blackstudies129/ Massey-Denton-Ch-ONE.pdf

Periódico Diagonal Global (2007). Los tentáculos españoles de la camorra napolitana. Recuperado de http://www.diagonalperiodico.net/global/ tentaculos-espanoles-la-camorra-napolitana.html

Periódico El Clarín. (2001). Los parias de las ciudades. Recuperado de http:/ / edant.clarin.com/suplementos/cultura/2001/04/01/u-00611.htm. Periódico El Clarín. (2006). Italia: lanzan un plan de seguridad en Nápoles para frenar a la mafia. Recuperado de http://edant.clarin.com/diario/2006/11/04/elmundo/i-04101.htm

Periódico El Clarín. (2013). El sector más peligroso de Buenos Aires. Recuperado de http://m.elespectador.com/impreso/temadeldia/articulo342849-el-sector-mas-peligroso-de-buenos-aires

Periódico El País. (2004). La teoría de las ventanas rotas. Recuperado de http:/ / elpais.com/diario/2004/10/18/catalunya/1098061644_850215.html

Periódico El Tiempo. (1993). Cinco Huecos, una calle caliente. Recuperado de http://www.eltiempo.com/archivo/documento/MAM-197168

Periódico Nueva Era. (2012). Tepito: La Meca del culto a lo probibido. Recuperado de http://www.nuevaeraonline.com.mx/tepito-la-meca-delculto-a-lo-prohibido/\#KcGVufBSSaogBbzh.99

Periódico La Crónica de Hoy. (2013). Tepito, zona propicia para cualquier actividad delictiva, admite PGJDF. Recuperado de http:/ / www.serviciosurbanosdf.com/sintesis/?tag=delincuencia

Portal El Observador. (2013). La Rocinha, realidad y ficción. Recuperado de http://www.elobservador.com.uy/noticia/243719/la-rocinharealidad-y-ficcion/

Portal El Observador. (2010). Las diez ciudades más inseguras del mundo. Recuperado de http://www.rnw.nl/espanol/article/las-diez-ciudadesmas-inseguras-del-mundo.

Sánchez, F., Espinoza, S. \& Rivas, A. (2003). ¿Garrote o zanahoria? Factores asociados a la disminución de la violencia homicida y el crimen en Bogotá, 1993-2002. Documento CEDE No 27: Universidad de Los Andes.

Smith, N., \& Low, S. (2006). The Politics of Public Space, Londres $\backslash$ : Routledge. 
Vozmediano Sanz, L., \& San Juan Guillen, C. (2010). Criminología ambiental. Ecología del delito y de la seguridad. México: Editorial OUC. Recuperado de http://www.seguridadpublicaenmexico.org.mx/55_pasos/ paso\% $2017 . p d f$

Wacquant, L. (2010). Las Cárceles de la Miseria. Buenos Aires: Ediciones Manantial. 